\title{
City at The Eyelevel The Visual Perception of The Plinth Case Study: Al-Moudiria St., Tanta, Egypt
}

\author{
Engy H. Saeed, Nermeen A. Omar \\ Architecture engineering department, engineering Faculty, Tanta University, Egypt \\ engy_hassan@f-eng.tanta.edu.eg nermeen_omar@,f-eng.tanta.edu.eg
}

\begin{abstract}
-. the plinth facades are suffering many problems resulting from the individual attempts to design the plinth between monotony design and chaos one without consider the history and the character of the street; these states caused a lack of visual stimulation for the pedestrians that translated into weakness and sometimes the absence of the visual perception of the plinth, little attention has been directed toward determine the good plinth aesthetics principles through arrange and order of its facades elements to achieve good visual perception. Thus, the purpose of the present study is to develop a suggested conceptual framework for enhancing the plinth facades to achieve the urbanities visual perception. The research methodology is based on two approaches; the theoretical study which identify the plinth facades elements and the aesthetics principles, and the analytical approach by using case study of "Al- Moudiria" St located in Tanta city. Data collected from the observation and the interviews were analyzed. The findings indicate that the elements of the plinth facades (Materials- colors- base panel- pilasters- fasciaopenings- awnings- lightings and singes) should be arranged according to the sense of the place and the aesthetics principles (composition- scale- rhythm- balance and symmetrytransparency) to achieve a good plinth which improve the urbanities visual perception of the plinth.
\end{abstract}

Keywords: plinth, visual perception, aesthetics, façades elements

\section{INTRODUCTION}

The good city for some people is to achieve its functional role by offing all the uses, good transportation....etc. but for many others, its success depends not only on its functional role but also on its rational, emotional and aesthetic experiences for urbanities in its public spaces [26].

The good experience for pedestrians is resulting from many aspects to make a good sense of the street. The facades of the street boundary buildings and its aesthetics are one of the important and effective aspect specials at the eye level (ground floor) as it plays a key role and major contribution to the pedestrian urbanities experiences. However, the ground floor which is known as "plinth" only occupied a small area $(10 \%)$ of the whole area of the building but it controls the urbanities perceptions of the street [39]. So, if the plinths are varied and interesting in its activities and details, the experience of the street becomes richer and invite. Furthermore, the plinths façades with aesthetics qualities provide the urbanities with distinguished visual perception which encourages the urbanities movement in the city and makes it a journey of pleasure, happiness, and enjoyment.
Over time the importance of the street and its plinth get through up and down status. Until the mid-20th century, the street and its plinth were united with the urbanities lives, but that has been changed when the vehicle transportation dominated the planning and urban design of the city and neglected the human needs and feels in its planning. Accordingly, many attempts form the urban designers and planners like Lynch, Jacobs and Cullen directed to reinforce the human scale and its effect on the pedestrian urbanities life in many aspects $[13,14]$. One of these aspects is the awareness of the plinth that raises and takes place because of the deterioration of the building facades of the which locate as boundaries of the street especially at the eye level. Hence, the relationship between the ground floors and city life becomes an important subject for discussion in many studies such as the study of the school of architecture, Royal Danish Academy of Art [15].

Although studies have examined many issues related to the plinth such as; the Ground-floor façades impact on the public life [21], the functionality of the plinth [26] and its trends [15], to the best knowledge of the researchers non have examined the good plinth aesthetics principles through arrange and order of its facades elements to achieve good visual perception. While Gehl Association, Stipo and the school of architecture, Royal Danish Academy of Art investigated criteria for good plinths, the influence of the facades elements according to the aesthetics principles of the plinth on the visual perception of the urbanities is a topic that needs further examination

\section{A. Problem definition}

Despite the increasing progress in urban studies interested in the lives of people to make them safer, easier and full of pleasure, they do not touch that in real life. This is apparently witnessed in urban spaces, where the streets suffer from the urban deterioration that appears through its boundaries, especially the ground floor "plinth" which is considered the most places where the interaction between the street and the people has occurred.

Despite the diversity of activities in the plinth nowadays, its design has become a personal trend without taking into account the context of the area and its historical buildings. That led to a plinth of chaos with a negatively impact on the visual perception of urbanities during the movement. Hence, there is a need to reach methods or guidelines taken into consideration the design or improvement of any plinth to be 
consistent with the character of the space and the design principles to arrange and organize the elements of the plinth.

\section{B. The Aim}

The need to adapt and design attractive good façades of the plinth is fundamental to achieve a distinguished visual perception for the urbanites at the city eye level. The research main aim is to determine a conceptual framework of the aesthetic principles for the plinth façade out of its elements. This main aim can be achieved through secondary aims including the exploring of the visual perception of the urban design, the identity of the plinth and studying and recognize the façade elements. This guideline is not planned just for a new building but also for historic and existing one by enhancing its plinth facades as a part of the whole plinth of the street to improve the urbanities visual perception.

Based on the previous objective, the following research questions emerge

1- What are the important aesthetics principles that contribute to better visual perception of the plinth?

2- What are the main elements of the plinth facades?

\section{The Research Methodology}

The research methodology is based on two approaches: firstly, the theoretical study which concerned of reviewing the meaning and importance of the visual perception for urban spaces generally and for the street and its plinth in particular, as well displaying the definition of the plinth and its role to achieve a good visual perception for the pedestrians. In this context the research suggests a conceptual framework to determine the plinth visual perception according to the façade elements under the aesthetics principles which should be adapted with the sense of the place considering the change of the context according to the place cultural and aesthetic characteristics.

Secondly, the analytical approach which analyses one of the important street plinths depending on the suggesting conceptual framework. For that research, Tanta city was chosen as a case study the research because it represents one of the Egyptian cities which face unplanned replacement of the historic context and building especially in its downtown without any urban development plans commitments. "Moudiria St."; which was selected as applied street, is considered as one of the most important street at the downtown of Tanta city, with its commercial and retail background image for the citizen of Tanta city, which suffers of the deterioration of its plinth. The analytical approach is using two tools; the field observation and the "face to face" convenience interviews with 22 individuals. The reason for using the observation and the interviews is to attain deeper understanding of the research problem. These tools used to define the current state of its plinth attempting to improve it by setting a number of discussions. Finally, conclude some recommendations which could be taking it in consideration in the future.

\section{THE VISUAL PERCEPTION}

The perception can be defined as the awareness of objects and the data, or the different ways for the human mind to sense the information of the external environment $[16,28]$.
The perception has implicated as Amos Rapoport mentioned in three meaning aspects; the environmental evaluation, the way people understand the environment and the environment sensory experience [16]. So, the perception can be considered as a holistic experience attained through stimulation of different senses; vision, hearing, smell and touch to explain and realize the environment [33]. One of the important studies of perception was the Gashtalt rules which explained the human perception as a whole or complete form not only the shape of the objects that congaing of [40, 41].

Since the beginning of the cities transformation which concentrates on its urban form at 1898, the urban design becomes the city art, and the perception of the city becomes important to enjoy this art [6]. Kevin Lynch pointed in his book "image of city" how the urbanities organize the city mentally into a coherent image or pattern which makes a quick and easy movement. Getting that image in perceived through three attributes; identity (a distinction of the object from others), meaning of the object (rather functional or /and emotional) and structure (the spatial relation with the other objects and to the urbanities) [22].

Since the vision is considered as a domain human sense, and the recognition of the places becomes clearer and covered by the vision which provides more information and details effectively [30]. The visual perception dimension become one of the main valuable dimensions of the urban design [6].

So, realizing the visual character of each space and its surroundings is measured not only from the structure parts of the space such as shape, texture, color, ...etc. but also from the intangible part of the specific patina from the users' activities overtime [40]. This gives the space the value and the meaning to make a better urban design by improve the urbanites experiences and encourage their movement with pleasure and satisfaction especially at the pedestrians' eyelevel [27].

\section{THE PLINTH}

The relation between the streets, the boundaries buildings and the urbanities began since the streets were just pathways, and the boundaries were simple vendors' booths. This relationship which was continued with the urbanites- who came and went or stayed- becomes the key element of the street life with its boundaries [15].

Thereafter, the boundaries buildings known as urban buildings become a fundamental part for urbanities that were able to walk around the city and making good and close encounters with it especially with the ground floors of these buildings known as "plinth". The plinth which is considered as a vibrant public space is where the building can touch and be touched. And it is considering it as vibrant public spaces. [21] as in Figure 1.

The plinth plays an essential role for the pedestrian urbanities visual experience through its façades which are affected by its characters on less or more visual dynamic status at the eyelevel of the city [34].

Over time, the plinth with the street had many changes with all the upwards and falls which effected on the urbanities. Till 1850, the plinth was contained mixed uses 
with a merge of trades, working, living uses in the same building.

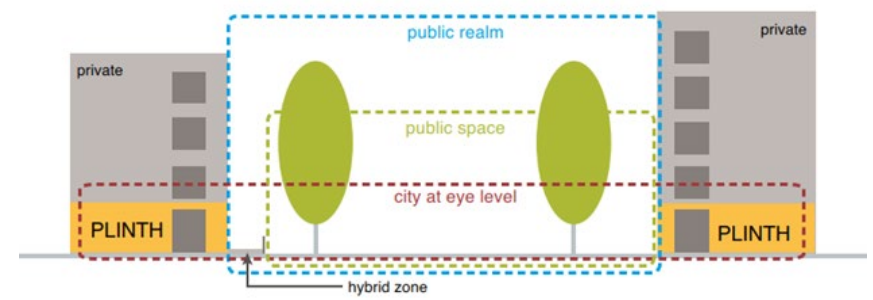

Figure 1. The relationship of the plinth with the street - source: Gehl, 2016.

The goods were displayed in booths at the front of the houses on the street, by the time these booths became part of the building facades as; porches, arcades or stoops. By the 19th century, the plinth transformed into a storefront to show all the goods through wide glass windows with different shapes, sizes and decorations, sometimes it had continued arcades and passage. At the period next the second war world till the modernism decades, the plinth was not just for shopping but for housing and living, sometimes with closed façades. Nowadays, the plinth becomes related to the public spaces strongly and attached with the shopping and entertainment experience but with losing the urban architecture image with the negative effect of the visual perception of its façade [42]. So, the plinth played various roles through time and the effect of it was obviously on the life of the users and their activities whether it was a pleasant or bad experience with its urban architecture as in Figure 2.

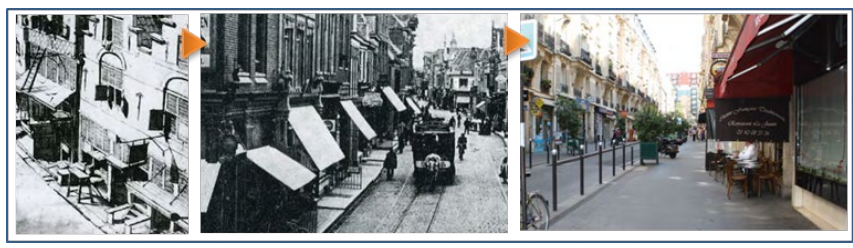

Figure 2. The plinth transformations with the street - source: Gehl,2016.

\section{THE PLINTH VISUAL PERCEPTION CONCEPTUAL FRAMEWORK}

Because of the importance of the plinth and its facades to reach the good visual perception for the pedestrian urbanities, it is necessary to explore the criteria of the plinth visual perception which is including many principles that can be guided in the design and assess the plinth facades

There were many attempts to understand "the good building" in the urban visual perception dimension. One of the most studies that were presented from the Royal Fine Art Commission (RFAC) that concerned and discussed the good building at the urban architecture "façade" level in six criteria including; order and unity, expression, integrity, plan and section, details and integration $[6,32]$. While Buchanan argued that the façade of the building at the urban level should; create a sense of place, mediate between inside and outside, have windows, have character, have composition and have decoration [34].

From many studies and attempts which concern of the urban architecture that focuses on the façade of the building especially at the eye level "plinth" and becomes the important and effective part of the building to recognize visual perception of the pedestrian urbanities [12]. Sitte [6] defined the facades of the buildings as the limits to space, and the aesthetic principles of it are big concerns, the research suggests a guideline of the visual perception for the plinth based on its criteria and their principles to achieve the good and pleasant experience as in Figure 2.

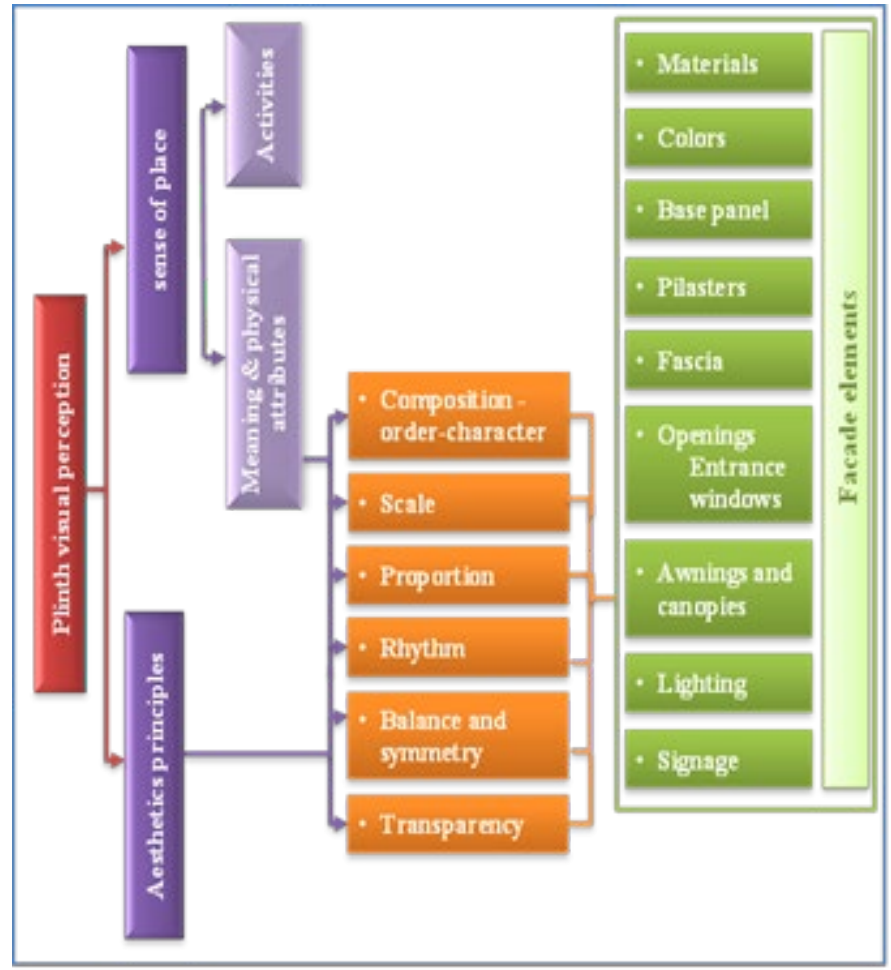

Figure 3. Conceptual framework of the plinth visual perception- source: Authors.

\section{A. Sense of place}

All the users need to sense a good relationship and strong belonging to a space and the whole city, that is considered as a challenge nowadays which doesn't appear in the past because of the unique identities of old cities which retained to their significant culture, architecture, social, aesthetics and technology that achieved a distinguished sense of place [33]. Since creating a sense of place is the main goal of urban design, many studies dealt with, Lynch mentioned that the sense of place is depending on the physical properties and the sensory ones beside the function or the uses, making a relationship and good feeling of the place spirit $[8,22]$. While Relph argued that when designers ignored the meanings of places meanings to people's minds, they destroyed veritable places to inauthentic ones [35].

Besides that, the unique place identity is the place sense meaning as Alford mentioned it as the relationship between

the urban environment and people in it. And therefore, there are three components that take part in producing a sense of the place; activities, physical qualities, and meaning. $[1,10]$. So, the meaning is achieved from the cultural influences of people, place and time which can reach through using the symbolism and imagery [3, 9]. 
Through time, this sense could be lost because of the aggressive urban changes and deterioration which extends to the urban spaces including the streets and their boundaries. That is leading to loss of the urbanities perception of these buildings and the whole street especially the pedestrians and their perception of the facades of the plinth which have their direct relationship.

Also, the expressing of the functions of the plinth- not only retail function but also residential, commercial and social functions- to turning the plinth from just a physical public spaces to spaces for support human interaction, economic exchange, and well-being to reach distinguished experiences at eye level for pedestrians [21].

The utilization of the identity which remnants from the past- by; conserving the old shop fronts and its historic elements, trying to unhangs its function or changes its function with suitable one with its history and the adjacent functions- is considered to reinforce the plinth sense [39].

\section{B. Aesthetics principles}

The urbanities can be recognized, remembered and affected easily by the distinctive façades and its elements which are considered the important urban elements that contribute visually to the street [2]. So, the arrangement and selection of these elements should be under specific visual principles including:

\section{Composition - order}

The composition of the objects or elements of the façades influences the human perception by creating an order or pattern which makes sense of these grouped elements as a whole rather than a single part or element in isolation to present a visually coherent façade [34, 37].

Meiss mentioned that the built environment was experienced with an easy or different way by explained it mentally and visually grouping different elements making a unique composition [6].

The composition or the pattern in the eye level or plinth façade could achieve by the grouping of various elements such as the fenestrations, bays, columns ...etc. That can be arranged in a specific order under other principles like symmetry, unity,....etc. as in Figure 4 [6].

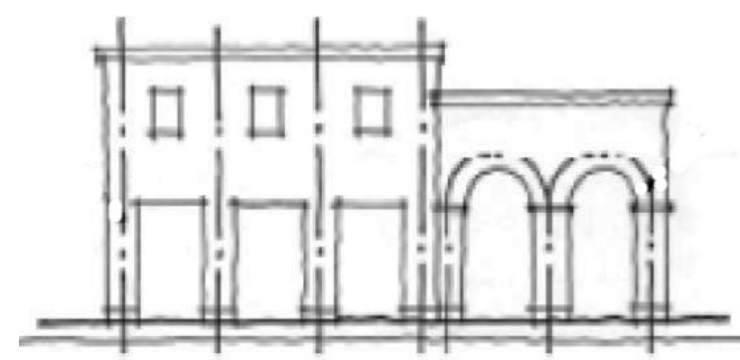

Figure 4. The composition and order of the plinth - source: report- City of Mesquite 2016

\section{Scale}

The Scale depends on comparing between one set of dimensions to others. In the urban design, it is depending on compared the human dimension and the urban spaces including its surrounding buildings [25] and refers to how urbanities perceive the size of the building and its façade elements.
In addition, many studies suggest that the human scale can be defined by the width of the building and the human speed in the space. So the human scale depends on the size, articulation, and texture of the elements that identify human proportion and size besides, the harmonizing with the pedestrians speed $[18,31]$.

For the plinth and eye level, the human scale is dominated. It is emphasized by the ability to reach and touch the details and textures of its façades at the pedestrians' level $[4,6]$. This can be reached when the pedestrians stand at quite a distance to see to the building and the upper stories gradually disappeared from their sight as in Figure 5.
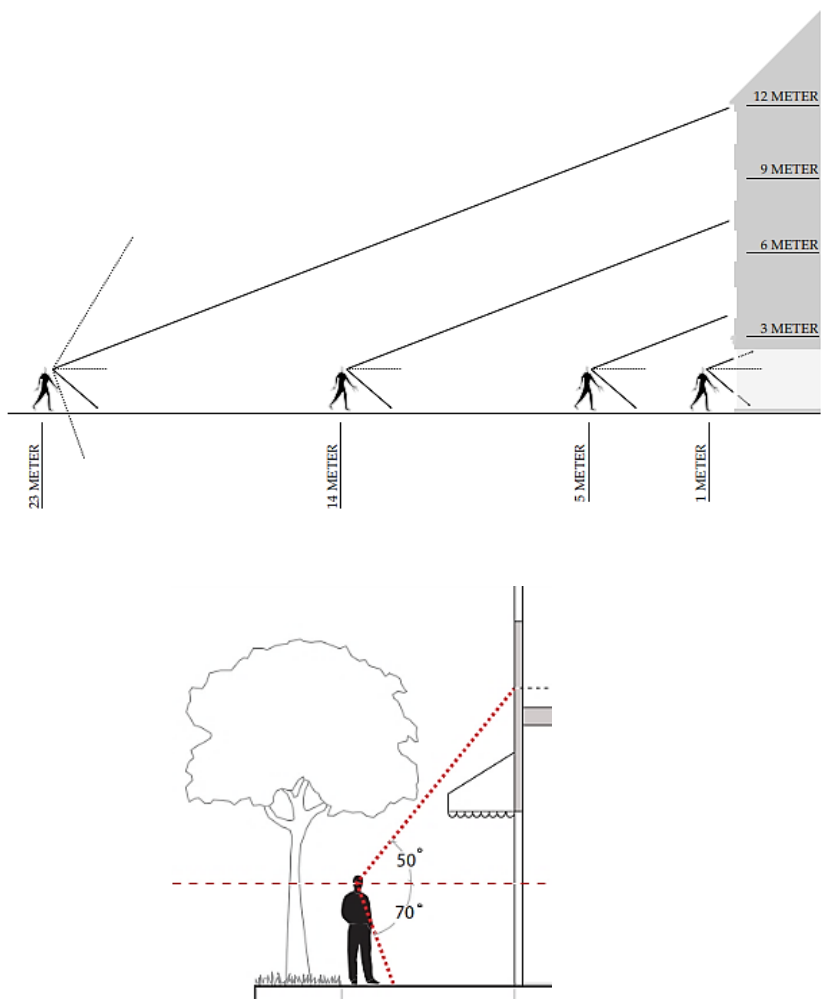

Figure 5. The vision angle and distances at eyelevel - source: Bloomberg, et.al. \& Gehl 2016

\section{Proportion}

Proportion refers to the ratio of one element or part to another, or to the composition or the whole building in harmony. In other meaning, it is the relation of two ratios [7, 37]. So, it is a way to weight the element of any composition in a visual way. Many studies try to reach the ideal proportions like the golden rectangle "1: 1.6" ratio to reach a sense of natural proportion [25].

In the plinth, it can relate the mass of the ground floor level to the openings like doors and windows in it which gives attention to the façades. Also, the proportion can be developed by adding many elements with a good arrangement to make interesting façades like bays using the columns [37]. Even the brick pattern can divide the large façade to proportion parts as in Figure 6 [50].

\section{Rhythm}

It is a system that is stimulated and affected by the users' minds. It is considered as a basic character in urban design and architecture. The rhythm achieved by arranging the elements to inspire a sense of movement and direction, this movement may be of the users' eyes or of their bodies [7, 25]. 


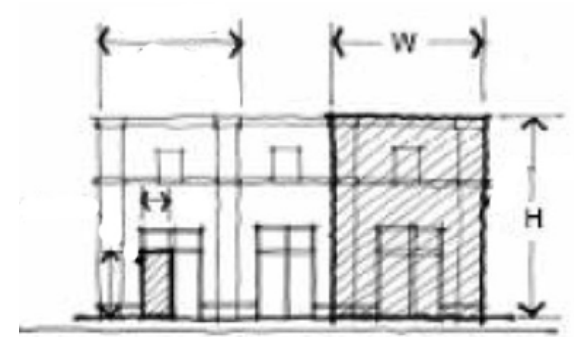

Figure 6. The proportion of the plinth, source: report- City of Mesquite 2016

So, it is important to make harmonious and regular repetition of shapes and forms through the details and spacing using columns and bays. Thus the rhythm provides continuity, and any break of its sequence leads to more attention to the interrupting element or spaces.

This can be reached in the plinth with the rhythm of the façade mass or its details elements such as the windows, doors, bays, columns, lighting...etc. which repeat along the façade of the ground floor to create a visual rhythm as in Figure 7.

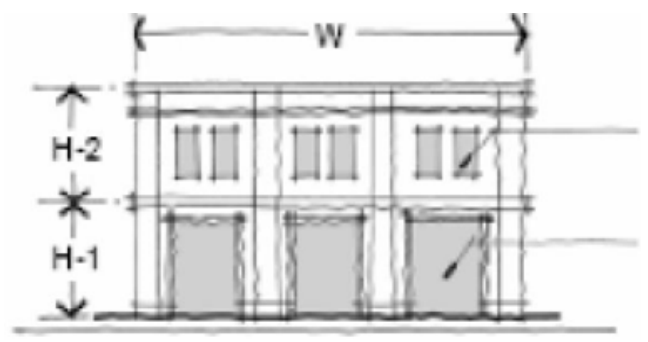

Figure 7. The rhythm of the plinth, source: report- City of Mesquite 2016

\section{Balance and symmetry}

The balance is visually a sense of the distribution of elements for any component by regulating it in a specific pattern or system. This arrangement could be achieved in two types or balanced outlooks [25].

- Symmetric type: achieving the visual balance from arranging the elements of the component with equal weights placed at equal distances of an axis (imaginary axis). It presents a mirror or equal image across this axis.

- Asymmetric type: achieving in formal balance through the non-axial arrangement of the components by setting the big weight close to the fulcrum of the balance to a small eight at a great distance of it

At the façade especially at eye level (plinth), the balance can be achieved by the arrangement of the elements such as repeating the bays and frames rather by a symmetric arrangement or asymmetric one which gives a good effect and make eye-catching façade or the fenestrations system or by that give sense of balance and order and therefore, the users have a pleasant view of the street as in Figure 8 [31].

\section{Transparency}

Transparency attributes to the ability for people to see or perceive activates beyond the wall of the building, therefore, it is an inherent condition of the material to connect or link through light or/ and air like the material of glass. So, the building façade has large areas to achieve transparency through their windows and doors which relate the users inside the building to be observed from the outside however it is private or public [31].

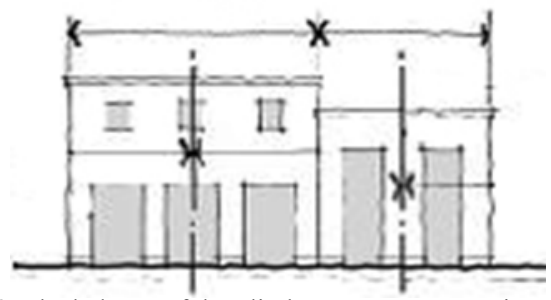

Figure 8. The balance of the plinth, source: report- City of Mesquite: 2016

The transparency is achieved in a high percentage at the eye level or the plinth façades especially through the storefront rather than the residential activities and the upper levels. This transparency enhances the urbanities activities at the plinth whether commercial or mixed uses by providing a visual connection between inside and outside the plinth [37].

However, the blank wall or the reflected glass is reducing the transparency degree. As Allan Jacobs said, that it can direct the human activity beyond the street $[19,37]$. So, the fenestrations (doors and windows) play the main key role to achieve the transparency of the plinth as in Figure 9.
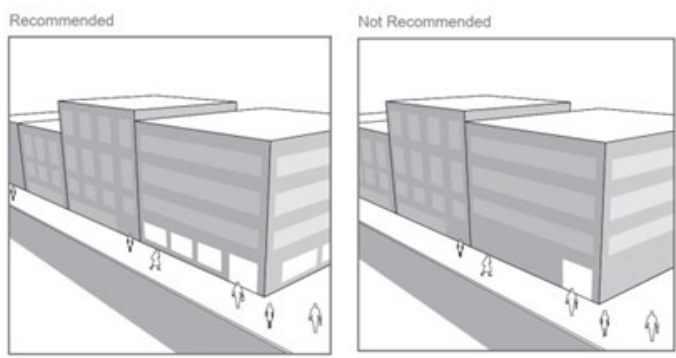

Figure 9. The transparency of the plinth, source: report- City of Mesquite: 2016

\section{C. $\quad$ Plinth Façade elements (components)}

\section{Materials}

Materials of the boundary building of the street are one of the main elements which affect the human perception especially the long-lasting materials that encourage the timelessness and continuity sense of the street. And with its qualities, it provides a sense of concern from the pedestrian urbanities.

The sense of the materials related to the type of these materials whether natural materials which are considered as the old material back centuries and it comes from the earth like wood- stone- brick, it provides a connection sense to the natural environment, while the new such as glass- metal steel which provides a sense of modernism beside sense of refining and smooth, it gives a contrasting sense in the façades between past and present $[5,51]$.

In the plinth, it is important to make harmony in using both types of materials with avoiding to achieve visual chaos. Thus, the selecting and using of the materials which need to make a good design can be merged both types in the articulation elements such as columns, windows, doors, signs...etc.

By considering the principles like rhythm, proportion, and scale in the using materials and its units such as the size of the brick and stone, it should enhance the sense of the human activities in the plinth [37]. 


\section{Colors}

Many studies such as Nasar studies suggests that the color is one of the factors to configure the built environment which affects the aesthetic perception by achieving harmony with its surrounding or contrast. While color is considered as a perceptual sensation that results from the response in the retina to the light waves which have three dimensions; hue, saturation, and luminance [29]. It can provide emphasis to part, character or element in the façade, or to separate parts, also to reach specific sense or spirit to the façade.

The color considers can divide into two categories; warm and cold colors, both give different feelings to the urbanites. Warm colors give a stimulating sense with visual weight to the elements with it and being more dominant than the cold colors [25]. On the other hand, the cold colors give a sense of smooth and calm and reflect the natural environment such as green spaces, sky. So, it enforces the sense of being grounded with calming sense [9].

\section{Openings (fenestrations)}

- Entrances- Doors

The entrance at the plinth façade should be invited and distinctive especially for the storefront that should be transparent also. But in advance, the entrance to the upper whether residential or other uses is better to move to the side street or it is at the main façade with many options; in its center to achieve a sense of symmetry, aligned with the entrance tower, with recessed on/of the façade with lobby, All of that with confirming by columns or decorative elements with high quality materials [43].

The door of the entrance should match with the materials, styles, and character of the window but with special distinguish details to be noticed for the pedestrians, and sometimes it could have solid lower part [52].

Sometimes the reassessed door has its benefits to provide protection for the pedestrians beside that it gives an identity to the store entrance while the service entrance should be at the side or at the back of the building to be screened from the sight of the pedestrians [46].

- Display window

The window is considered one of the important and effective elements of the plinth facades. Whatever most of the plinth is commercial and retail activities or services uses, the windows of the storefronts are essential parts. So it should provide visual interest by allowing the pedestrians to view the goods and the store interior $[46,52]$.

The window offers a variety in shape, style, colors, and arrangement. It can determine the style and character of the building [detail streetscape] beside conserved the old ones with its frame and divided spaces or bays, while the modern one should be harmony with the traditional style. [48]

\section{- Clerestory window}

Which occupies the upper part of the display window and door (entrance), it is important as its upper extension which should be preserved [48]. The sense of unity of the street plinth can be contributed from the size or the scale and the proportion of the window to the solid, the rhythm of spacing and the details of the window [51].

\section{Base panel-stall- riser}

The section where the plinth façade meets the ground - it plays as the base for the plinth- it is an important part for protection from the rainwater or the pedestrian movement, It must be constructed of suitable materials to hold out all these conditions these materials could be hard stone, glazed bricks...etc. which is selected to be appropriate with the character of the façade $[47,52]$. Besides that, it plays a part to modify the proportion in the plinth facades especially the storefront and makes it balanced. And more purpose is to raise the goods of the store in the display windows to the eye level [52].

\section{Pilasters}

It is one of the vertical elements at the wall; it could be a protruding part of the wall or applied part as half of a column [51]. It is a way to divide the façade to numbers of pays, and make a suitable rhythm, proportion and human scale of the facades of the plinth whither retail, mixed uses or residential to make it from large dull blink facades to an interesting one [47]. In the storefront, it framed its façade and makes a degree of emphasis between the storefront and each other [52].

\section{Fascia}

It is the upper horizontal part of the plinth façade with its cornice. And it is the divided part between the plinth and the upper stories. Usually, it is the controlling and prevailing spaces of the storefront which is including the store name or the main sign of it [adoption] it should be in proportion to the storefront and to the whole building with matching design with the character of the building. It shouldn't overtake more than a quarter of the rest of the plinth façade height [52].

\section{Signage}

It is the announcing of the activity or the use for the plinth however it is commercial and retail, mixed-use, offices or residential. The size, form, and type are different according to the uses [44, 48]:

- Street number signs applied to the façade wall near the entrance.

- Building block signs which announce the information like construction year, the architect and the use or activity name.

- Business signs which indicate the type of the business and its logo.

- Storefront sign which placed above the display, clearstory window and the door of the store in the fascia area with height average $45-50 \mathrm{~cm}$.

- Door and window sign which announce the business at the pedestrian eye height (names or logo) with a size not exceed one square foot.

- Hanging/ perpendicular sign which suitable with the narrow façade or in the upper stories. with height at above $2.4 \mathrm{~m}$

So, the signs are the most effective elements to make eye-catching and attention of the pedestrians. It should be integrated with the plinth façade and taking into account the adjacent business (proportion, size, color...etc.) and the character of the buildings and the style of the product which is being announced. 


\section{Awnings and canopies}

These elements occupying spaces on the upper facades of the plinth which used to protect the pedestrians from the sun and rain, it achieves a comforting environment that enhances the contact with the plinth.

It could be a fabric structure with a metal frame or a flat metal structure either horizontal or slope, making cantilever from the plinth façades with extending not exceed than 4 feet. Both types must respect the rhythm of the façade and locate between each pilaster or columns. It may be also placed above the clerestory windows or at the level which display window couldn't cover with the awning slope [51].

It is important to select the appropriate form, material and color for the awnings that matching with the character of the façade and with the arrangement of the windows, doors, and signs [48]. The architecture arcades or fixed canopy is another form of the awnings that used according to the history and character of the façade of the plinth [52].

\section{Lighting}

It is important elements for achieving safety for the pedestrians and to highlight the signs and details of the plinth façade. It is essential to avoid the flashing and pulsating lights that distracted the pedestrian with its glare [52]. And the highlighting signage is a kind to light the storefront. So, it should be matching with the style of the façade architecture. It could be on the residential entrances or distributed on the commercial, retail, services and offices facades, with warm inviting lighting which attracts the pedestrians to the plinth.

Through reviewing all aspects related to design the plinth (principles- element) under the respect of the urban context and its character and identity. The research summarizes guidelines that should take in consider to design or improve a good plinth to achieve visual perception for its urbanites:

- Identify historic visual character and identity of the place (city-Street). And make it as the reference that the plinth design (style and the character) can depend on to reach the unique sense of place for its urbanities.

- The elements of the plinth can order and arranged to concern the identity and the historic background and culture of the place, and also, according to the aesthetic principles.

- The composition or the pattern of plinth façade elements should be arranged in a specific order under other principles like symmetry, unity, proportion which modify with the historic character of the place.

- Consider the human scale as the plinth essential scale.

- the Proportion between the mass of the plinth to the openings. And between elements themselves achieve good plinth for urbanities.

- Rhythm is one of the main principles to achieve good plinth by improving the rhythm plinth façade mass beside the rhythm of its details elements to reach a kind of unity to the whole street.

- The elements arrangement according to symmetric or asymmetric order made a balance for urbanities.

- Transparency is essential for the plinth to play its role, so the opening must be with suitable size to encourage the contact between the plinth and urbanities.
- So, it is important to choose and arrange the plinth elements according to its character and take in considered of [Figure 10]:

- Choosing quality materials that matching with the historic materials to enhance the image of the plinth for its urbanities.

- Choosing colors that consistent with the character of the place and compatible with each other

- The opening withers entrances or windows should be invited and encouraging the urbanities with suitable proportion with the plinth mass, beside that it is important to be clear with a distinctive image

- the Base panel should be with suitable materials with the character of the façade. It plays a big role in modifying the proportion of plinth.

- Pilasters are the main way to divide the façade to numbers of pays to make a suitable rhythm, proportion and human scale of the plinth facades.

- The Fascia should match with the building character. it shouldn't overtake more than a quarter of the plinth façade height considering the suitable proportion to the storefront.

- It is important to select awnings with the appropriate form, material and color that matches with the façade character and with the arrangement of the openings.

- The signs should be integrated with the plinth façade and taking into account the adjacent business (proportion, size, color...etc.) and the buildings character

- Lightings should be matching with the style concerning the façade architecture and suitable for the type of the store.

\section{THE ANALYTICAL STUDY OF "MoudiRIA ST." PLINTH}

This part of the research seeks to analyze the plinth of one of the most famous street "Moudiria St." to investigate the effect of the street plinth and its façade on enhancing the pedestrian visual perception according to the suggested guideline.

The analytical study using two tools; field observation by walking examining the façade elements and its extent to achieve the aesthetics principles according to the guideline. The second tool is "face to face" interviews with pedestrians who have their experiences with the street plinth. the Informal interviews were conducted with 22 individuals in Al-Moudiria St. within the first week of April 2019. Each interview lasts between 8 to 10 minutes. Of the people being interviewed, 12 were females and 10 males, whereas 13 aged from 40-60 years and 9 of them between 18 and 35 years. Moreover, 16 were from Tanta city and the reset from neighborhood villages. Out of those 22 persons, 14 with bachelor degree, 3 with post grade degree, 3 were under graduated students, and the rest with no degree.

The study chooses "Moudiria St." which defined as one of the most important streets in the downtown of Tanta city as it includes properties with various activities mostly the retail, commercial and offices at its plinth. These properties extended along the street from El Sa'aa square - in the northto Al-Mahatta St. (station st.) in the south as in Figure 11. 

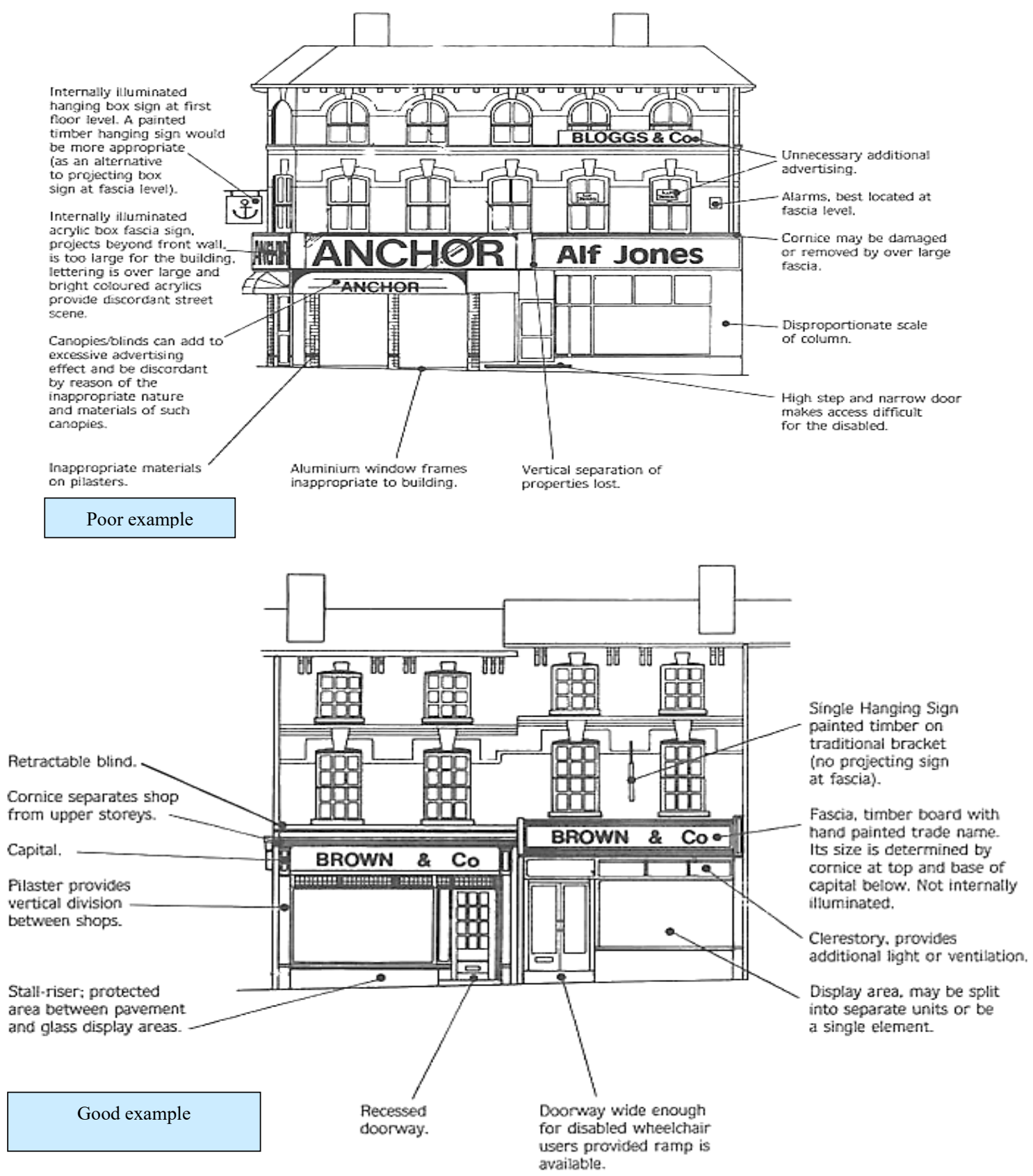

Figure 10. Example of poor and good shop front composition at the plinth, source: guide to storefront design

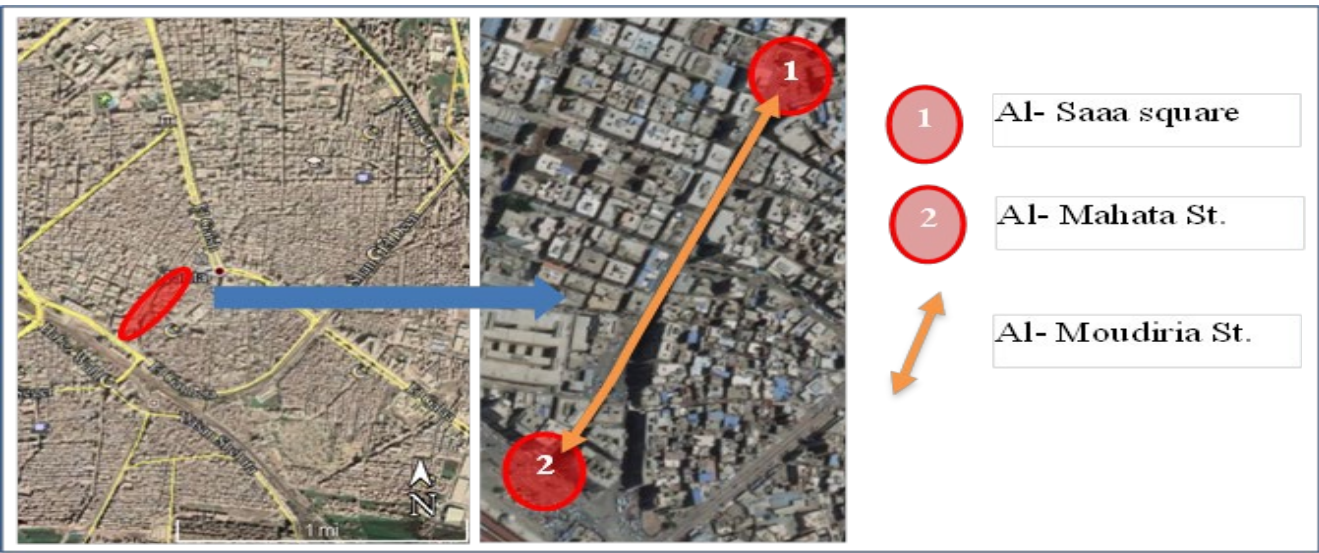

Fig. 11 The location of Al- Moudiria St. - source: Google earth. 


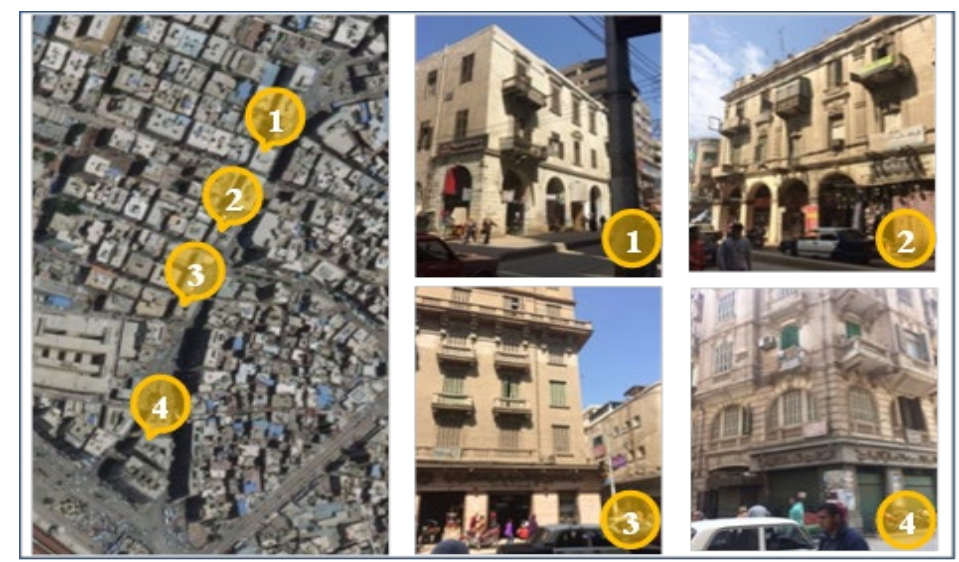

Figure 12. Historic buildings in Al-Moudiria St.- source: Google earth- Authors

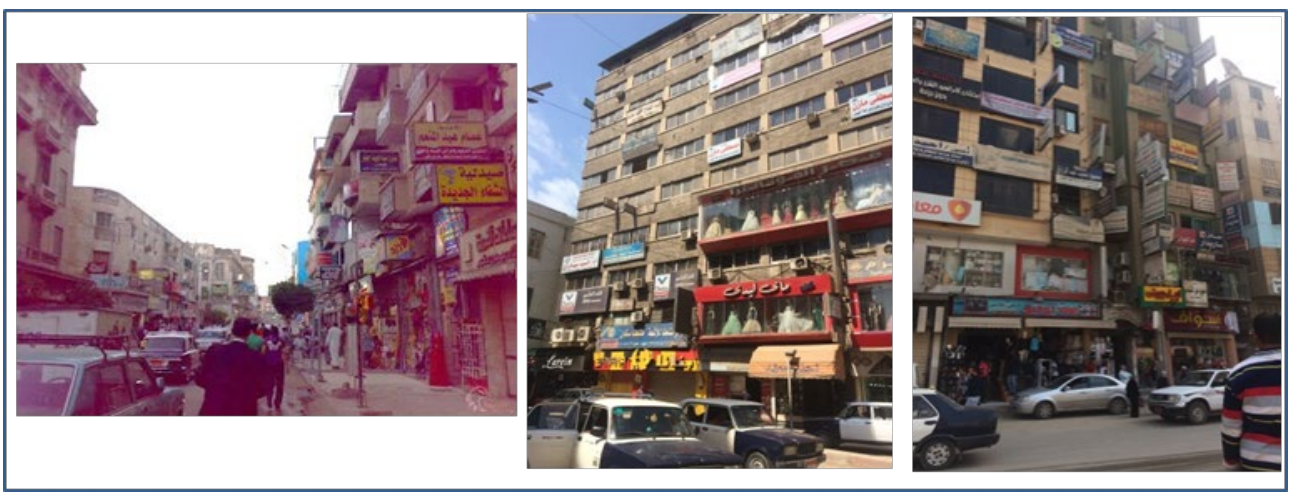

Figure 13. Images of Al-Moudiria St. Plinth with various uses and no character- source: Authors

The diversity of the uses throughout the plinth is considered as the key role for maintaining vitality and success for the users, regardless the chaos of the urban characters and the buildings deterioration which of most historic buildings, with unique plinth and replacing it with buildings without respect to the distinctive old character, the street image, and identity.

Both the west and east facades of the street contain few old historic buildings in Tanta city being structured at the beginning of the twenty century with continuous arcades along the street as a distinctive as in Figure 12.

The meaning of the street as one of the most commercial destinations in the city hasn't changed, but it suffers from the demonstration of the identity which was unique to the pedestrians from the beginning however it changed since the 70th of the twenty century till now. This statue has been resulted from historic buildings demolition and replaced with no character buildings including its ground floors. So the plinth of the street has an important meaning for the pedestrian in the activity and use side but lost its sense of place as a good image as in Figure 13.

At the past, the plinth of the street distinct by its consistency of the scale and proportion with the same height of the ground floor approximately $5-6 \mathrm{~m}$, the storefront typically narrows between $3-4 \mathrm{~m}$ which achieved the sense of human scale with the unique rhythm of the openings and arcades. There was a significant role of the articulation of the plinth façades in its historic buildings such as pilasters, columns, bays, arches with bricks and stones materials beside the matching colors along the street.

These aesthetics principles with the elements of facades established a unique image of the street plinth that contributes to a plinth positive experience and reinforces the visual perception as in Figure 14.

Unfortunately, the design of modern buildings which established in 70th in adjacent to the few remaining historic buildings hasn't committed to the unique image and identity of the old plinth. This appeared through:

There is absence of the distinctive arcades of the plinth with no respect to the using of rhythm in the storefront and its elements like bays, pilasters, columns, windows...etc.

The different height of the plinth than the historic plinth eliminates the continuity of the scale and proportion of the plinth along the street. Beside the interventions of the signs, lights, colors, materials...etc.

All of that produce a sense of chaos with a weak degree of visual perception for the pedestrians making the plinth in and around difficult to navigate. That has been noticed through both the observation and the face to face interviews as shown table 1 .

\section{DISCUSSION}

The "Moudiria St." should have a plan to improve its urban architecture, especially for its plinth to match with its important value and image as the main commercial, retail, and services destination. 


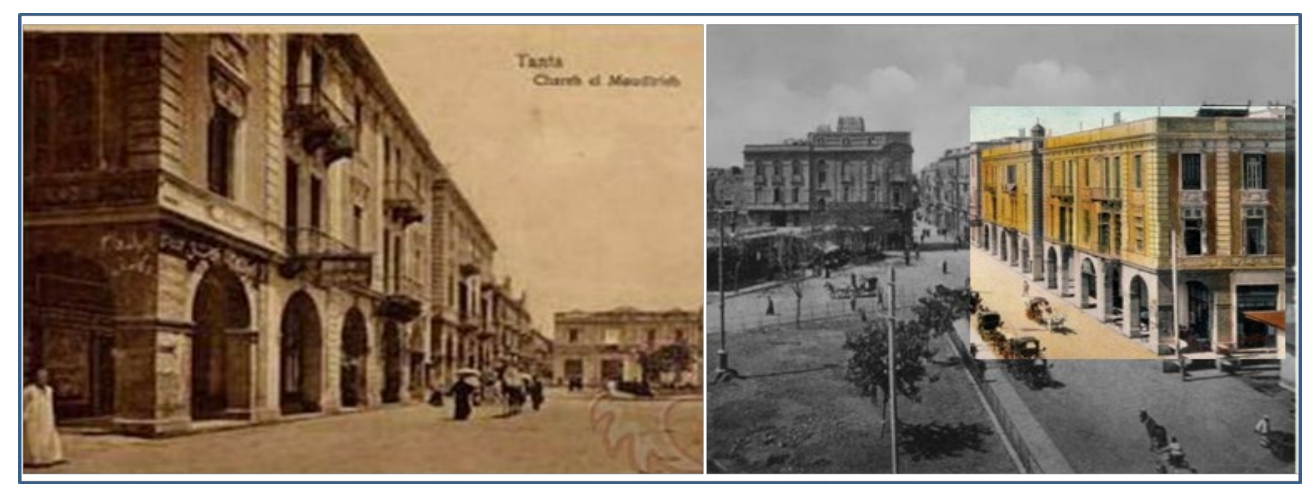

Figure 14. Images for the historic Al-Moudiria St. and its plinth from and to Al-Saaa squaresource: newtanta Blog. newtanta.blogspot.com

However, the presence of many of activities and uses at the street plinth but it needs to organize these uses and the announcing of them in a good image to enhance the pedestrian visual perception of the street that encourages them to visit the street and enjoy their journey in it, especially with their history and experiences with the street.

The improvement of the historic plinth should be revealing the building's original character and its elements which should be preserved as possible. Taking into account that the replacement of their distinctive elements should be made carefully with respect of the original image of the plinth that presents more attention for it and also a positive visual perception.

For the buildings which have no character, it should be harmony with the historic building, by adopting many suggestions:

- Reducing or limiting the expression of the individual personality which reduced the sense of the plinth by set numbers of the regulations for the plinth especially for the at the historic part of the city through studying its visual character according to the codes and the land uses zones distribution.

- New important and renovations should reinforce the existing historic plinth for the whole of the street.

- Divide the plinth into symmetrical rhythm facades or bays which respect the modular of the old rhythm of the arcades sometimes with using the columns and arches (3-4m).

- Maintain the rhythm of the opening (display windowsentrances) to improve and emphasizes the continuity of the movement at the plinth.

- Respect the height of the plinth as approximately 5-6 m using the fascis which separate the plinth level of the building, taking into account the appropriate width/height proportion of the whole plinth - especial for the storefront.

- Using the materials matching with the old materials like bricks and stones with its unit's scale that improves the sense of the human scale for the pedestrians.

- Considering the effects of the colors with using suitable colors whether for materials, signs, and awnings that should be coordinated with each other and with the nature and history of the plinth.
- Trying to reduce the effect of the reassessed of the modern building than the old ones with adding a number of the awnings and canopies to reach the protection sense for the pedestrians along the plinth.

- Removing all the signs and reset and arrange the selecting ones to be more harmony with its size, types, style, materials, and colors.

- Achieve a high degree of transparency for the plinth by redesign the window with a suitable size and proportion and also with rearranging of the goods to allow the pedestrians to explore the inside.

- To maintain an attractive image, the light should be suitable to the style of the plinth with avoided the glare one or the indirect. And using the good distribution along the plinth whether in the lights units or in the light signs.

- Materials should be compatible with the old materials but with considering the color and the type of the original ones and avoid using the false materials that not match with the historic plinth, taking into account the surface cleaning of these materials with an easy way.

\section{RECOMMENDATIONS}

- The good design of the plinth whether with storefront, houses, offices, or businesses, it leads to highly effective and quality not just functionally but also visually.

- The life of urbanites in the street is connected not just on the functions of its boundary buildings but in high degree depending in its visual image to improve their visual perception of it and encourage the pedestrians to visit the street frequently.

- The visual experience of the pedestrians is depending on the sense of the plinth so it is important to respect the identity and the meaning of the plinth for them and conserve it in any renovation or redevelopment.

- The regulations and guidelines should be set for each city according to its character and image to limit the individual contravention on the plinth along with the city. These guidelines not only for the existing buildings but must take it into account for the new upcoming buildings at the vacancy. 
Table: 1. The Al-Moudiria St. plinth analyzing source: Authors

\begin{tabular}{|l|l|l|l|l|}
\hline & \\
\hline & \\
\hline
\end{tabular}




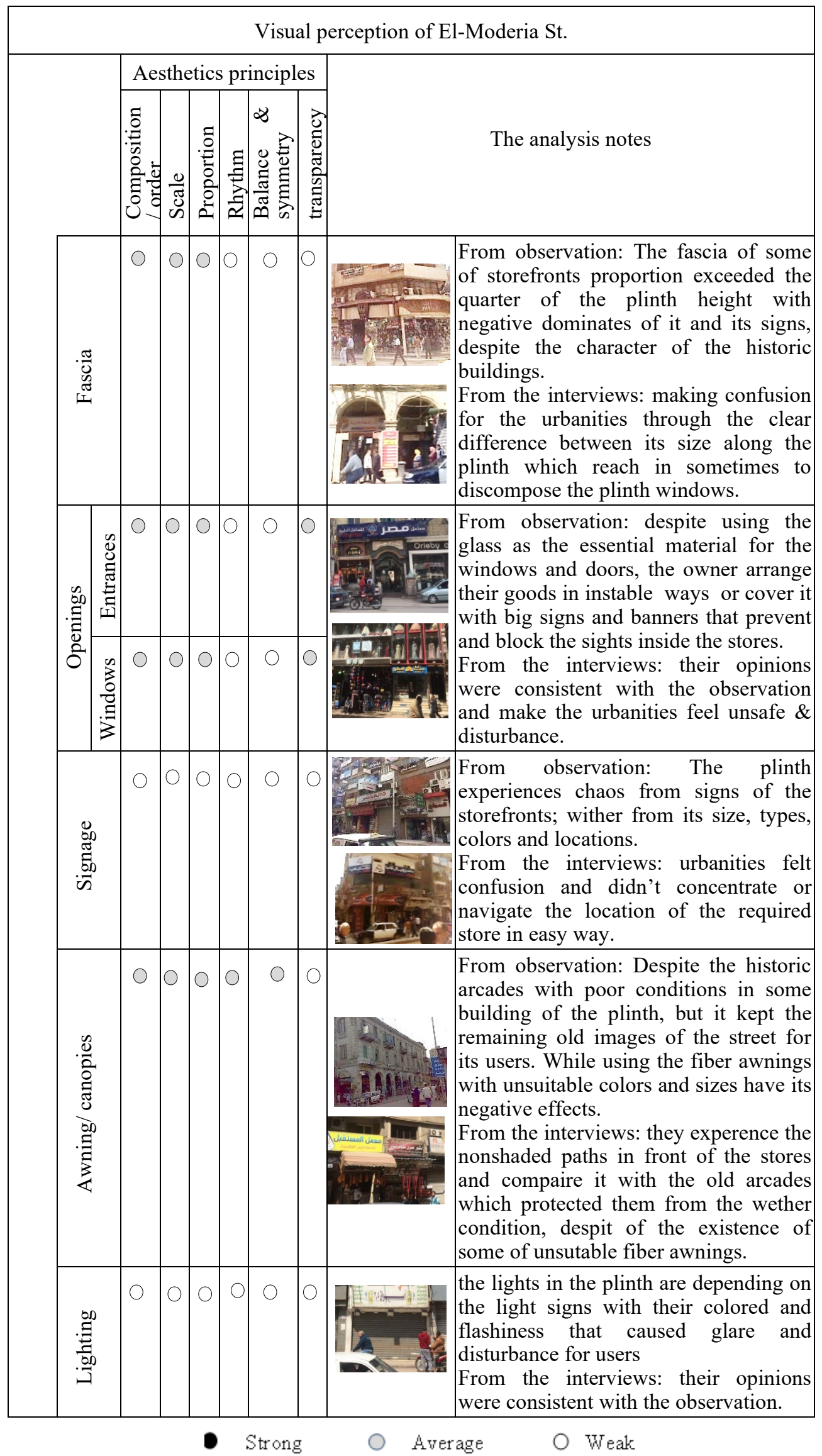


- The observation of the community should be present to recognize for any shifting of the function or the character of the plinth image.

- While the commercial plinth takes the most attention for the developing and improving, the residential plinths need more attention to its visual image by applying the aesthetics principles with its elements such as opening, bays, signs...etc.

- It is important to improve the façade of the plinth not for a single or individual building but for the whole plinth façade along the street.

- The good plinths are important of the owners' interests. The economic benefits will increase when the visual perception at the plinth increasing and becomes a pleasure and enjoyable journey for the pedestrians.

\section{References}

[1] Al-Obeidy, Musaab Sami. Dabdoob Rawia Marwan. Reviewing On Street Attributes In Influencing Sense Of Place And Place Attachment. International Journal Of Advanced Research (Ijar), 2017.

[2] Askari, Amir Hossein. Soltani, Soha. "Contribution of Building Façades to Attractive Streetscapes: Study of Two Main Streets in Kuala Lumpur City". Journal of Design and Built Environment Vol. 18(1), June 2018.

[3] Berleant, Arnold. "Aesthetic perception in environmental design"

[4] BERTLIN, JOEL. "Social Sustainability from the perspective of three concepts: human scale, the city at eye level, and public life". Degree Project in Urban and Regional Planning, Advanced Cycle, Stockholm 2014.

[5] Bloomberg, Michael R. et al., "Active Design- shaping the sidewalk experience", City of New York, 2013.

[6] Carmona, Matthew.et.al. "Public Places - Urban Spaces- The Dimensions of Urban Design". Architectural Press. 2003.

[7] Ching, Francis D.K. "ARCHITECTURE Form, Space, \& Order", John Wiley \& Sons, Inc. 2007.

[8] Damayanti, Rully. Kossak, Florian. "Extending Kevin Lynch's Concept Of Imageability In Third Space Reading; Case Study Of Kampungs, Surabaya-Indonesia", Itu A|Z 2016.

[9] Dietrich. Kurt, "Architectural- Design Elements".

[10] Ewing, Reid. \& Handy, Susan, "Measuring the Unmeasurable: Urban Design Qualities

[11] Ewing, Reid. et al. "Identifying and Measuring Urban Design Qualities Related to Walkability", Journal of Physical Activity and Health 2006.

[12] Galindo, Ma-Paz. Hidalgo, Ma- Carmen. "Aesthetic preferences and the attribution of meaning: Environmental categorization processes in the evaluation of urban scenes", International Journal of Psychology, 2005.

[13] Gehl, Jan. "Cities for People", Island Press, 2013.

[14] Gehl, Jan. "Life between buildings: using public space". The Danish Architectural Press

[15] Gehl, Jan. et.al. "Close encounters with Buildings", URBAN DESIGN International, 2006.

[16] Gjerde, Morten. "Evaluating The Visual Qualities Of Urban Streetscapes", Master thesis. School of the Built Environment, Oxford Brookes University, February 2009.

[17] Graham, Lisa. "Gestalt Theory in Interactive Media Design", Journal of Humanities\& social Science, 2008.

[18] Herd, Milt. "Achieving Human Scale Building Facades Fronting Streets", FAICP.

[19] Jacobs,Allan B."Great Streets", Mit Press, 1993.

[20] Joseph Ehardt, Jr. AICP, CNU HDR Jacksonville, FL. "Great Streets: Opportunities for Sustainable Change. APWA Congress \& Exposition 2008 New Orleans

[21] Karssenberg, Hans. et.al. "The City at Eye Level", Second and extended version. Eburon Academic Publishers. Delft, the Netherlands, 2016.

[22] Lynch, Kevin. "The Image of the City", Massachusetts Institute of Technology, the M.I.T. Press, Cambridge, Massachusetts 1960.
[23] Marlina, Endy. et.al. "Advertising Arrangements: An Attempt In Improving The Visual Quality Of Urban Areas", International Journal of Recent Contributions from Engineering, Science \& IT (iJES), 2014.

[24] Mokhtar, Makhlouf. "Aesthetics Values In Urban Design (Case Study Constantine)" Thiese. Universite Mentouri, Republique Algerienne, 2007.

[25] Moughtin, Cliff. Oc. Taner, Tiesdell, Steven. Urban Design Ornament and Decoration, Architectural Press 1999.

[26] Muller, Thaddeus. "The Plinths of the Warm City", The City at Eye Level. Eburon Academic Publishers. Delft, the Netherlands, 2016.

[27] Nasar, Jack L. "Urban Design Aesthetics: The Evaluative Qualities of Building", Environment and Behavior. May 1, 1994

[28] Nisha, Bobby. Place and Perception: Constructing the urban narrative with spatial schemas Conscious Cities Anthology, Human-Centred Design, Science, and Technology,2018

[29] O'Connor, Zena. "Façade colour and aesthetic response: Examining patterns of response within the context of urban design and planning policy in Sydney", Doctor thesis, 2008.

[30] Polat, Ahmet Tuğrul. "Visual Quality Assessment In Landscape Architecture", 19th International Academic Conference, Florence, September 2015.

[31] Related to Walkability" Journal of Urban Design, Vol. 14, February 2009.

[32] Sadeghiet al." Explanation of Environmental Aesthetic Factors of Urban Design", Current World Environment, 2014.

[33] Saikia, Arnav. Urban Design Dimensions: Perceptual Dimension, Vasturaag Design Group, 2015.

[34] Saikia, Arnav. Urban Design Dimensions: Visual Dimension, Vasturaag Design Group, 2015.

[35] Seamon, David. \& Sowers, Jacob. "Place and Placelessness", Relph. Edward, Chapter of Key Texts in Human Geography, London: Sage, 2008.

[36] Shamai, Shmuel. \& Ilatov, Zinaida. "Measuring Sense of Place: Methodological Aspects", The Royal Dutch Geographical Society, Knag. 2005.

[37] Sottile, Christian. "The Humane Principles of Good Buildings", Preservation Society of Charleston. 2017.

[38] Spreiregen, Paul D., Urban Design: The Architecture of Towns and Cities, McGraw Hill press, 1965.

[39] Stipo. 80 Lessons To A Good City At Eye Level. Stipo Team. Eburon Academic Publishers, 2012.

[40] Trancik, R. "Finding Lost Space; Theories of Urban Design", Van Nostrand Reinhold Company, New York, 1986.

[41] Uzunoglu, S. Sema. Uzunoglu, Kozan. "The application of formal perception of gestalt in architectural education", Social and Behavioral Sciences, 2011

[42] Werf, Jouke van der., Zweerink, Kim. \& Teeffelen, Jan van. "History of The City, Street And Plinth", The City at Eye Level. Eburon Academic Publishers. Delft, the Netherlands, 2016.

\section{Reports}

[43] BOOK II: DEVELOPMENT REGULATIONS. REDWOOD CITY DOWNTOWN PRECISE PLAN 15FacadeCompositionRegulat

[44] Building Façade City Of Los Angeles Department Of City Planning

[45] Building façade LA Walkability Checklist.

[46] Eisaman, Karl E. "CITY OF GREENSBURG - Design Guidelines for Building Facades. The City of Greensburg 2007 designguidelinesforbuildingfacadesandsigns 0

[47] FAÇADE- guide to storefront design. New York City Department of Small Business Services FACADE_updated facade guide

[48] Façade Improvement Program, Department of Community and Economic Development Town of Clinton, Massachusetts.

[49] Principles and Requirements for Façade Design City of Mesquite: Community Development Department 2008. CAM w-amends 2016_201705041423429537

[50] Shop front design guide. Rushmoor Borough Council February 2015

[51] The City of Kawartha Lakes, Streetscape and Facade Design Guidelines - Lindsay Report Final- January 18, 2016.

[52] Urban Design Guide Supplementary Planning Document. Spatial Planning and Transport. Islington Council. January 2017. 20170131 islingtonurbandesignguidespdjan2017

\section{Sites}

[53] http://www.Googleearth.com [Accessed: 10-1-2019]

[54] http://newtanta.blogspot.com/2011/05/blog-post.html [Accessed: 11-12019]. 